\title{
Swiss Study to Validate the Mannheimer Craving Scale (MaCS)
}

\section{Schweizer Studie zur Validierung der deutschen Mannheimer Craving Scale (MaCS)}

Fabian Reichenbach $^{1}$, Yuliya Burren ${ }^{1}$, Christoph Flückiger ${ }^{2}$, Hansjörg Znoj $^{3}$, Franz Moggi ${ }^{1}$

${ }^{1}$ University Hospital of Psychiatry and Psychotherapy, University of Bern, Bern, Switzerland

${ }^{2}$ Department of Psychology, University of Zurich, Zurich, Switzerland

${ }^{3}$ Department of Psychology, University of Bern, Bern, Switzerland

Corresponding Author:

Prof. Dr. Franz Moggi

University Hospital of Psychiatry and Psychotherapy, University of Bern, Bern, Switzerland Bolligenstrasse 111

CH-3000 Bern 60, Switzerland

Phone: +41 319309111

E-mail: moggi@puk.unibe.ch

Fassung Nr. 6.1; 13.10 .17

Angabe Anzahl Wörter und Anschläge: 4‘965 bzw. 32 ‘839 (einschliesslich Literaturverzeichnis, aber ohne Abbildungen und Tabellen)

Zusammenfassung und Abstract: 205 bzw. 210 Worte

Tabellen: 2, Abbildungen: 2 


\begin{abstract}
Aim: In the research and treatment of Substance Use Disorders (SUDs), craving for alcohol, nicotine, and drugs is an important concept associated with addictive processes, including relapse after treatment. The 12-item Mannheimer Craving Scale (MaCS) has been proved to be an economic, reliable, and valid self-rating instrument across several substances in German samples. The aim of this study was to examine its psychometric characteristics in a Swiss German sample. Method: Overall, 166 patients were recruited from an inpatient SUD treatment program at the University Hospital of Psychiatry in Bern, Switzerland. Results: The internal consistency was high and the test-retest reliability was satisfactory. The total scale and three specific analogue craving measures were highly correlated. Principal component analysis extracted two factors, explaining $61 \%$ of the total variance, and these factors were confirmed through confirmatory factor analysis. However, the two factors correlated highly, and several items loaded on both factors, so that the factor structure was inconclusive. Conclusions: The psychometric characteristics of the MaCS in a Swiss German sample are as good as those characteristics of the German version, suggesting that it is a valid and reliable measure. The MaCS factor structure must be examined on a larger sample that integrates a broader range of SUD severity.
\end{abstract}

Keywords: Craving, MaCS, questionnaire, factor structure, psychometric characteristics 


\section{Zusammenfassung}

Ziel: Für das Verständnis von allen Störungen durch Substanzkonsum ist Suchtdruck ein wichtiges Konzept. Die 12 Items umfassende Mannheimer Craving Scale (MaCS) erwies sich in deutschen Stichproben als ökonomische, reliable und valide Selbstbeurteilungsskala allgemeinen Suchtdrucks. Das Ziel der Studie ist, deren psychometrischen Eigenschaften in einem deutschschweizerischen Patientenkollektiv zu überprüfen. Methode: In zwei Programmen für den qualifizierten Entzug von Substanzkonsumstörungen der Universitätsklinik für Psychiatrie und Psychotherapie Bern wurden bei 166 Patienten neben der MaCS auch soziodemographische und klinische Merkmalen erhoben. Ergebnisse: Die interne Konsistenz der MaCS war hoch und die Retest-Reliabilität befriedigend. Die explorative Hauptkomponentenanalyse extrahierte zwei Faktoren, die 61\% der Gesamtvarianz erklärten und die in der konfirmatorischen Faktoranalyse bestätigt wurden. Die beiden Faktoren korrelierten stark miteinander und mehrere Items luden auf beiden Faktoren so hoch, dass die Faktorstruktur nicht schlüssig war. Schlussfolgerung: Die psychometrischen Eigenschaften der MaCS sind in Deutschland und der Schweiz ähnlich, so dass für beide Länder ein valides und reliables Instrument vorliegt. Die Faktorenstruktur muss in einer grösseren Stichprobe mit einem breiteren Spektrum an Substanzkonsumstörungen geprüft werden.

Schlüsselworte: Suchtdruck, MaCS, Fragebogen, Faktorenstruktur, Psychometrische Merkmale 


\section{Swiss Study to Validate the Mannheimer Craving Scale (MaCS)}

\section{Introduction}

"Alcohol is a valued product which has provided important functions for people throughout all history" (Hanson, 1995, p. 1). Peele and Brodsky (2000) reported in a review that there are positive effects of moderate alcohol use (e.g., enhancement of mood, sociability, and social integration). However, alcohol is also attributable to about $3.8 \%$ of all early deaths globally (Rehm et al., 2009), and 7.5\% of people residing in Europe have been diagnosed with an Alcohol Use Disorder (AUD; World Health Organization, 2014a).

A core concept in understanding Alcohol Use Disorders (AUD) is craving (Soyka \& Küfner, 2008), which is defined as "a strong desire or urge to use alcohol” (American Psychiatric Association, 2013, p. 491). Craving is primarily a subjective experience (Anton, 1999), but still a multidimensional construct, modulated by individual differences and environmental context (Skinner \& Aubin, 2010). Craving is linked to the amount of alcohol consumption and risk of relapse after treatment (Drobes \& Thomas, 1999). Bottlender and Soyka (2004) reported in a prospective study that strong craving predicts relapse in abstinent alcohol-dependent patients. Tiffany, Carter, and Singleton (2000) reported that craving was measured only by one item in several important studies on pharmacological interventions for alcohol dependence, making it impossible to calculate a scale's reliability. One item also limits the extent to which one can detect correlational or experimental effects of craving and alcohol outcomes. According to Sayette et al. (2000), it is theoretically and clinically imperative to measure craving with valid and reliable instruments. 
The Obsessive Compulsive Drinking Scale (OCDS) is a well-established, 14-item selfreport instrument for measure craving, developed by Anton, Moak, and Latham $(1995,1996)$; the measure has also been validated in Germany (Mann \& Ackermann, 2000; Nakovics, Diehl, Croissant, \& Mann, 2008) and Switzerland (Burren, Wapp, Seitz, Ballinari, \& Moggi, 2012). The OCDS is an adapted and modified version of the Yale-Brown Obsessive Compulsive Scale for heavy drinking (Y-BOCS-hd; Modell, Glaser, Mountz, Schmaltz, \& Cyr, 1992), which is based on the Yale-Brown Obsessive Compulsive Scale (Y-BOCS; Goodman, Price, Rasmussen, Mazure, Delgado, et al., 1989; Goodman, Price, Rasmussen, Mazure, Fleischmann, et al., 1989), a rating instrument for obsessive-compulsive disorders (OCD; World Health Organization, 2014b). In a review, Anton (2000) concluded that the OCDS can be seen as a valid outcome measure as well as a valuable predictive and diagnostic tool.

There are reliable and validated substance-specific instruments available for drugs other than alcohol; for example, the Cocaine Craving Questionnaire (CCQ; Tiffany, Singleton, Haertzen, \& Henningfield, 1993), Heroin Craving Questionnaire (HCQ; Tiffany, Fields, Singleton, Haertzen, \& Henningfield, 1993), Benzodiazepine Questionnaire (BCQ; Mol et al., 2003), and the Short Form of the Marijuana Craving Questionnaire (MCQ-SF; Heishman et al., 2009). However, some clinical and research situations require information on use of multiple substances, such as alcohol and nicotine addiction, a common comorbidity, with more than $80 \%$ of alcohol-dependent patients also smoking (Batel, Pessione, Maitre, \& Rueff, 1995; Donath et al., 2007).

Because of this lack of reliable and valid instruments for craving across several substances, Nakovics, Diehl, Geiselhart, and Mann (2009) adapted and validated the Mannheimer Craving Scale (MaCS) to the language-specific craving behaviors based on the 
OCDS (Anton et al., 1995, 1996). The MaCS assesses overall craving across several substances, proving appropriate to measure multiple substance abuse. The MaCS showed high reliability coefficients $(.87<\alpha<.93)$, with test-retest-reliability values of $.45<r_{\mathrm{tt}}<.68$; its total score correlated significantly with three analogue scales for the intensity of craving $(r=.56)$, maximum craving $(r=.59)$, and frequency of craving $(r=.54)$.

Nonetheless, the psychometric characteristics of the MaCS have never been tested in the German speaking part of Switzerland, despite the fact that SUD habits might vary across these countries, as well as factors that might or might not impact these indices. The present study examines the psychometric characteristics of the MaCS in a Swiss German sample undergoing residential treatment for Substance Use Disorder (SUD); these include reliability, convergent and discriminant validity, and the factor structure (principal component analysis and confirmatory factor analysis). The present work extends the use of the MaCS to a broader German-speaking population of patients with SUD.

\section{Materials and Methods}

\subsection{Participants}

This study was executed at the University Hospital of Psychiatry and Psychotherapy in Bern, a facility that offers two residential treatment programs for SUD patients. Based on the inclusion criteria (see Procedure), 202 patients were invited to participate from 2014 to 2015. Of these, $12(5.9 \%)$ did not meet the ICD-10 criteria for an SUD (World Health Organization, 2014 b, p. 114) and $24(11.9 \%)$ withdrew informed consent so that they needed to be excluded. In total, $166(82.2 \%)$ patients were included in the study and gave written informed consent. The study was conducted according to the Swiss Human Research Act (HRA; Swiss Federal Council 
2014). All participants understood and spoke German and had been clinically diagnosed with an SUD at admission, according to the ICD-10 (World Health Organization, 2014b, p. 114). On average, patients were 43.2 years old $(S D=11.6)$, with an age range of 18 to 65 years. Of these patients, $59 \%$ were men $(n=98)$ and $41 \%$ women $(n=68)$. For further demographic characteristics, see Table 1.

The center requires patients to completely abstain from all substances, with the exception of nicotine and caffeine, and to not take prescribed medication during treatment. Regular drug tests are performed and any substance use results in withdrawal of permission to go out or discharge from the program. Patients left the center for scheduled appointments (e.g., appointments with psychologists or social workers). The center offers a standard inpatient treatment for SUD (e.g., psychotherapy, physiotherapy, music therapy), according to an individualized treatment schedule. A typical treatment lasts between three and six weeks, offering the option to participate in an additional outpatient treatment program for aftercare (Wittchen \& Hoyer, 2011).

\subsection{Procedure}

The data for this study were obtained from an observational Quality Management study, an ongoing longitudinal naturalistic cohort study on the course of SUD, which started in April 2014. The inclusion criteria for participants were as follows: (1) to have the ability to give informed, voluntary and written consent to participate, (2) to be an inpatient in the hospital wards for SUD, (3) to have the language skills to understand and answer the questions in German, (4) to have the cognitive competence and ability to complete the assessment, and (5) to be aged between 18 and 65 years. The assessment took place three times a week, in a separate, quiet testing room, lasting 30 to 90 minutes. In each case, a psychologist led the assessment and 
explained the procedure. Patients completed the first assessment within seven days after admission and the second assessment within seven days prior to discharge. The questionnaire could be completed on a tablet-computer or on the paper-pencil version. Participants were not provided with any compensation for their participation.

\subsection{Assessments}

The MaCS is based on the OCDS (Anton et al., 1995, 1996) and the modified German version of the OCDS-G (Nakovics et al., 2008), consisting of 12 items and 4 additional items, all of which are not substance-specific (Nakovics et al., 2009). Two items in the original 14-item OCDS, relating to the amount of consumption, were not included. Like the OCDS, the 12-item MaCS can be split into two subscales on obsessive thoughts and compulsive behavior. The questions pertain to enduring and recurrent thoughts about alcohol, the compulsive desire to consume alcohol, and loss of control over that desire. All 12 items have the same polarity, have five possible answers with increasing response intensity, and were coded from 0 to 4 . The four additional items are also based on the OCDS and include three visual analogue scales related to average craving, maximum craving, and the frequency of craving during the last seven days. Finally, one item records the duration of abstinence.

Craving was also assessed with an additional item ("Ich habe immer noch einen unwiderstehlichen Wunsch oder das Reissen, Alkohol zu konsumieren," "I still have a craving or a strong desire to consume alcohol") that was adapted from the DSM-5 diagnostic criterion for Alcohol-Related Disorders (American Psychiatric Association, 2013, p. 491). The item was coded with increasing intensity from 0 to 4. 


\subsection{Statistical Analysis}

The data were analyzed using the Statistical Package for the Social Sciences (SPSS) and the program, Analysis of Moment Structures (AMOS), version 23.0 for Windows. The MaCS total score was made up by the sum of the 12 items of the MaCS. Prior to analysis, the MaCS total score was examined for normal distribution. To explore the factor structure of the MaCS, exploratory factor analysis (EFA) with varimax rotation and Kaiser normalization was conducted. Confirmatory factor analysis (CFA) was performed to evaluate the data fit of the two models; the structure of the 2-factor model was guided by theory. The items and the latent variables were arranged according the initial model from Anton et al. (1995, 1996). A 1-factor model was also conducted to test the unidimensionality of the MaCS scale (Nakovics et al., 2009). For the CFA, AMOS was used. A mock examination showed that the model did not fit the data well when $\chi^{2}$ was significant (Amelang, Bartussek, Stemmler, \& Hagemann, 2006). As fit indices, the comparative fit index (CFI) and the root mean square error of approximation (RMSEA) were chosen. A CFI value greater than 0.90 shows a good model fit (Amelang et al., 2006). According to Browne and Cudeck (1992), RMSEA values <0.05 constitute good fit, values $0.05-0.08$ acceptable fit, values $0.08-0.10$ marginal fit, and values $>0.10$ a poor fit of the model.

Internal consistency was determined through Cronbach's alpha. Test-retest reliability was analyzed with two subsamples and entailed a correlation of the MaCS total score at admission and discharge. One sample $(n=47)$ had a maximum interval period of 28 days between admission and discharge, and the other sample $(n=24)$ a maximum interval period of 10 days. To measure construct validity, correlations between the MaCS score and the 4 additional items and the adapted DSM-5 item were obtained, and the three consumer groups 
were compared. To compare the MaCS total scores of the three consumer groups (alcohol, licit drugs, and illicit drugs), a Kruskal-Wallis test was used because the conditions for a one-way between subjects analysis of variance (ANOVA) were not met (no normal distribution). MannWhitney tests were used as post hoc tests, to follow up on this finding. A Bonferroni correction was applied so that all effects are reported at a .0167 level of significance.

\section{Results}

\subsection{Item Characteristics}

The 12 items of the MaCS showed small differences in the mean and the standard deviation. The item discrimination power is sufficient and in a good range (Table 2). A ShapiroWilk test was used to test for normality of the MaCS total score; $W(155)=0.981, p=.030$ was non-normal, indicating that the data were not normally distributed.

\subsection{Principal Component Analysis (PCA)}

Results of the orthogonal varimax rotated PCA are presented in Table 2. The KaiserMeyer-Olkin $(\mathrm{KMO})$ measure verified the sampling adequacy for the analysis. $\mathrm{KMO}=.90$, and all KMO values for individual items were $>.83$, which is well above the acceptable limit of .5 (Kaiser, 1970). Bartlett's test of sphericity $\chi^{2}(66)=926.39, p<.001$, indicated that correlations between items were sufficiently large for PCA. According to the criterion eigenvalue $>1$ (Kaiser, 1960), a 2-factor solution resulted, and the scree test (Cattell, 1966) confirmed the 2factor solution. The two factors collectively explained $61.74 \%$ (factor 1: $49.98 \%$, factor 2: $11.76 \%)$ of the variance. According to Anton et al. (1995, 1996), factor 1 could be interpreted as "obsessions" and factor 2 as "compulsions." However, the loadings are not as the model suggested. Item 3 has a stronger loading on the second factor. Moreover, items 10 and 11 loaded 
on the first factor, instead of the second. Moreover, it is not clear as to which factor items 9 and 12 loaded on. The content and structure of items 3, 7, and 8 are similar. They can be interpreted as "interference in everyday life." Table 2 shows the loadings for the 1-factor solution, which explains $48.76 \%$ of the variance.

\subsection{Confirmatory Factor Analysis (CFA)}

To examine the factor structure, two CFAs were calculated. As proposed by Anton et al. (1995, 1996), a model with two latent variables was evaluated, and so was a model with one latent variable, as proposed by Nakovics et al. (2009). Because of the above-reported PCA results, residuals were allowed to correlate between items 3, 7, and 8 . The CFI of the two-factor model (Figure 1) was equal to .949 and the RMSEA was equal to .074, which supports the fit of the model from marginal to good. The test statistic, $\chi^{2}(50)=95.27, p<.001$, indicated that the model and the data did not fit together well enough. The correlation between the factors was .86, suggesting that orthogonal independency was not met. The fit indices of the one factor model

(Figure 2$)$ were marginal to good $(\mathrm{CFI}=.913, \mathrm{RMSEA}=.096)$ and the chi-square statistic $\left(\chi^{2}\right.$ $(51)=128.36, p<.001)$ significant. In terms of the chi-square test, the models did not fit the data, but the fit indices indicated adequate fit.

\subsection{Reliability}

At admission, internal consistency was represented by Cronbach's $\alpha=.91$, and .88 at discharge. The test-retest reliability for the 10-day interval was $r_{\mathrm{tt}}=65$ and .56 for the 28-day interval.

\subsection{Discriminant Validity}

The MaCS total score (amount of craving) was significantly affected by the main substance abused, $H(2)=6.1, p<.05$. There were no significant differences between alcohol 
and licit substances $(U=1049, z=-.22, p=.416)$ and licit substances and drugs $(U=222, z=-$ $1.94, p=.026)$. However, when comparing alcohol with illicit substances, the MaCS total score was significantly lower for alcohol abusers than for illicit substance abusers $(U=1154, z=-$ 2.34, $p=.009)$.

\subsection{Convergent Validity}

To assess convergent validity, the four additional items and the adapted DSM-5 item were correlated with the MaCS total score. The adapted DSM-5 item, which is derived from the DSM-5 criterion for an AUD, was moderately correlated with the MaCS total score, $r=.41, p<$ .001 (for item, see page 7). The four additional items correlated highly with the MaCS (A13, $r=$ $.52, p<.001 ; \mathrm{A} 14, r=.51, p<.001 ; \mathrm{A} 15, r=.49, p<.001 ; \mathrm{A} 16, r=-.27, p=.001$; for items A13-A16, see Table 2).

\section{Discussion}

The present study was designed to examine the psychometric characteristics of the MaCS with a Swiss German sample undergoing residential treatment for SUD. The results indicated that the MaCS has good psychometric characteristics and that can be used on a broader German-speaking population as a valid, reliable, economic (low-cost), and easy-to-use instrument in clinical work and research.

According to Nakovics et al. (2009), the structure of the MaCS should be unidimensional. However, the theoretical background of the MaCS is the OCDS (Anton et al., 1995, 1996), where the factor structure is not stable. Some authors found 4 factors (Bohn, Barton, \& Barron, 1996) and others found a stable 2-factors solution (Nakovics et al., 2008). Similarly, the distinction between the 2 factors, "obsessions" and "compulsions," is not clear in 
this study. The Kaiser criterion as well as the scree plot pointed to a 2-factor solution, but the loading structure and the explained variance are different. There is one main factor, which explains almost $50 \%$ of the variance, and an additional factor, which explains a relatively small amount of variance (11.76\%). Moreover, the first six items should load on the factor, "obsessions," but item 3 loaded more strongly on the factor, "compulsions." In addition, the loadings for factor 2, “compulsions," differed for many items. Items 9 and 12 loaded almost equally on factor 1 and 2, although they should theoretically load on factor 2. Items 10 and 11 clearly load on factor 1, instead of factor 2. Interestingly, Nakovics et al. (2009) found a similar structure, but did not discuss that result. In their study, item 3 also loaded on "compulsions" and not on "obsessions." Further, items 10 to 12 loaded on the factor, "obsessions," instead of "compulsions."

The test statistic $\chi^{2}$ of both models of the CFA was significant, which means that the data did not fit the model well enough, but the fit indices for both models were in a sufficient range. Additionally, it was necessary to correlate the error variances of items 3,7 , and 8 . The 2factor model had a better fit than did the 1-factor model. However, there was a high correlation between the two factors, suggesting that these factors are not independent from each other.

Regarding the factor structure (PCA and CFA), this study indicates a 2-factor structure, in contrast to Nakovics et al. (2009). The MaCS was adapted from the OCDS, but that does not mean that they must have the same structure, in particular because there is no consensus about the exact structure of the OCDS in the research community. Further, the items of the MaCS are phrased unspecifically in terms of substance, enabling differences in the understanding and meaning of questions for participants. Another explanation could be the heterogeneous and unbalanced sample in terms of substances used, probably shifting the factor structure. However, 
this is the exact intention of this questionnaire, thus making it difficult to obtain a stable factor structure. In future research, a sample comprising different subsamples of substances is necessary for the examination of the factor structure of the MaCS.

The internal consistency (Cronbach's alpha) of the MaCS was high. Moreover, the testretest reliability values were also in a good range. As expected, craving decreases during residential treatment (Anton et al., 1996; Demmel \& Schröder, 2003), which has an impact on test-retest reliability (lower correlation coefficient). An important restriction using Cronbach's alpha is that high internal consistency is not evidence for a homogeneous scale or even the unidimensionality of the scale. According to Schmitt (1996), internal consistency is certainly necessary, but not sufficient for homogeneity. This has to be considered when discussing the factor structure (see below).

In terms of discriminant validity the lower craving level of alcohol abusers when compared to drug abusers was expected, with Nakovics et al. (2009) having found the same result. In contrast to these authors, only illicit substance abusers were compared to alcohol abusers in this study. Illicit substance abusers were not split into separate groups according to their mainly used illicit substance, because the groups would have been too small to test using inferential statistics.

In terms of convergent validity, this study found lower but still significant correlation coefficients between the MaCS total score and the additional items, compared to those found by Nakovics et al. (2009). An additional indicator of convergent validity is the significant correlation of the MaCS total score and the adapted DSM-5 craving item.

This study has several limitations. First, the subjects were recruited in a residential setting immediately after detoxification. Patients' craving might differ from that in an outpatient 
setting. Oslin, Cary, Slaymaker, Colleran, and Blow (2009) showed that craving decreases continually during inpatient treatments. Second, this study's sample might have been selective, representing only substance abusers who seek residential treatment for SUD. Third, due to the fact that some data were not normally distributed, it was not possible to perform an ANOVA; thus, the Mann-Whitney test, which has a lower statistical power, was conducted. Fourth, there were about five times more participants in the sample with an AUD, compared to participants who abused licit or illicit substances, resulting in a higher distribution of AUD participants in all statistical tests. Thus, larger samples of patients might be necessary to cover the full range of SUDs. In addition, due to the relatively small groups of illicit- and licit-use disorder patients, it was not possible to look at every group on its own. Finally, an important factor is the construct of craving itself. As stated in the introduction, craving is multidimensional and the fact that the MaCS asks patients only about the cognitive dimension of craving does not capture physiological and behavioral dimensions of craving.

Overall, the psychometric characteristics of the MaCS in a Swiss German sample are as good as those characteristics of the German version. This suggests that MaCS is a valid and reliable measure. The MaCS factor structure must be examined on a larger sample that integrates a broader range of SUD severity. 


\section{Conclusion for the practice}

- The MaCS has good psychometric characteristics and that can be used on a broader German-speaking population as a valid, reliable, economic (low-cost), and easy-to-use instrument in clinical work and research.

- The MaCS is a short 12-item self-report measure for assessing the cognitive dimension of craving across several substances, and might facilitate naturalistic research in routine practice and epidemiological studies.

- The factor structure of the MaCS suggests two dimensions; however, the exact “obsessions" and "compulsions" dimensions were not fully confirmed in the present Swiss sample.

\section{Acknowledgment}

The authors thank the patients who participated at the study and the Translational Research Center, Clinical Research, University Hospital of Psychiatry, University of Bern, Bern, Switzerland for support.

\section{Conflict of Interests}

None. 


\section{Reference}

Amelang, M., Bartussek, D., Stemmler, G., \& Hagemann, D. (2006). Differentielle Psychologie und Persönlichkeitsforschung (6., vollst. überarb. Aufl ed.). Stuttgart: Kohlhammer.

American Psychiatric Association. (2013). Diagnostic and statistical manual of mental disorders (5th ed.). Washington, D.C.: American Psychiatric Association.

Anton, R. F. (1999). What is craving. Alcohol Research and Health, 23(3), 165-173.

Anton, R. F. (2000). Obsessive-compulsive aspects of craving: Development of the Obsessive Compulsive Drinking Scale. Addiction, 95(8s2), 211-217.

Anton, R. F., Moak, D. H., \& Latham, P. K. (1995). The Obsessive Compulsive Drinking Scale: A self-rated instrument for the quantification of thoughts about alcohol and drinking behavior. Alcoholism: Clinical and Experimental Research, 19(1), 92-99.

Anton, R. F., Moak, D. H., \& Latham, P. K. (1996). The obsessive compulsive drinking scale: A new method of assessing outcome in alcoholism treatment studies. Archives of General Psychiatry, 53(3), 225-231.

Batel, P., Pessione, F., Maitre, C., \& Rueff, B. (1995). Relationship between alcohol and tobacco dependencies among alcoholics who smoke. Addiction, 90(7), 977-980.

Bohn, M. J., Barton, B. A., \& Barron, K. E. (1996). Psychometric properties and validity of the Obsessive-Compulsive Drinking Scale. Alcoholism: Clinical and Experimental Research, 20(5), 817-823.

Bottlender, M., \& Soyka, M. (2004). Impact of craving on alcohol relapse during, and 12 months following, outpatient treatment. Alcohol and Alcoholism, 39(4), 357-361.

Browne, M. W., \& Cudeck, R. (1992). Alternative ways of assessing model fit. Sociological Methods \& Research, 21(2), 230-258. 
Burren, Y., Wapp, M., Seitz, A., Ballinari, P., \& Moggi, F. (2012). Obsessive Compulsive Drinking Scale (OCDS-G): Psychometrische Kennwerte alkoholabhängiger Patienten in der Schweiz. Sucht, 58(2), 119-125.

Cattell, R. B. (1966). The scree test for the number of factors. Multivariate Behavioral Research, 1(2), 245-276.

Demmel, R., \& Schröder, M. (2003). Verlangen nach Alkohol, Depressivität und Ängstlichkeit während stationärer Entzugsbehandlung. Zeitschrift für Klinische Psychologie und Psychotherapie; Forschung und Praxis, 32(4), 303-306.

Donath, C., Piontek, D., Flöter, S., Gradl, S., Metz, K., Kröger, C., \& Bühringer, G. (2007). Alkoholabhängige mit Tabakkonsum in stationärer Rehabilitation in Deutschland: Prävalenz, änderungsmotivation und psychische Belastung. Sucht, 53(3), 143-152.

Drobes, D. J., \& Thomas, S. E. (1999). Assessing craving for alcohol. Alcohol Research \& Health, 23(3), 179-186.

Goodman, W. K., Price, L. H., Rasmussen, S. A., Mazure, C., Delgado, P., Heninger, G. R., \& Charney, D. S. (1989). The Yale-Brown Obsessive Compulsive Scale: II. Validity. Archives of General Psychiatry.

Goodman, W. K., Price, L. H., Rasmussen, S. A., Mazure, C., Fleischmann, R. L., Hill, C. L., . . . Charney, D. S. (1989). The Yale-Brown Obsessive Compulsive Scale: I. Development, use, and reliability. Archives of General Psychiatry, 46(11), 1006.

Hanson, D. J. (1995). Preventing alcohol abuse: Alcohol, culture, and control: Greenwood Publishing Group. 
Heishman, S. J., Evans, R. J., Singleton, E. G., Levin, K. H., Copersino, M. L., \& Gorelick, D. A. (2009). Reliability and validity of a short form of the Marijuana Craving Questionnaire. Drug and Alcohol Dependence, 102(1), 35-40.

Kaiser, H. F. (1960). The application of electronic computers to factor analysis. Educational and Psychological Measurement.

Kaiser, H. F. (1970). A second generation little jiffy. Psychometrika, 35(4), 401-415.

Mann, K., \& Ackermann, K. (2000). Die OCDS-G: Psychometrische Kennwerte der deutschen Version der Obsessive Compulsive Drinking Scale. Sucht, 46(2), 90-100.

Modell, J. G., Glaser, F. B., Mountz, J. M., Schmaltz, S., \& Cyr, L. (1992). Obsessive and compulsive characteristics of alcohol abuse and dependence: Quantification by a newly developed questionnaire. Alcoholism: Clinical and Experimental Research, 16(2), 266271.

Mol, A., Voshaar, R., Gorgels, W., Breteler, M., Van Balkom, A., Van de Lisdonk, E., .. . Zitman, F. (2003). Development and psychometric evaluation of the Benzodiazepine Craving Questionnaire. Addiction, 98(8), 1143-1152.

Nakovics, H., Diehl, A., Croissant, B., \& Mann, K. (2008). Modifications of the Obsessive Compulsive Drinking Scale (OCDS-G) for use in longitudinal studies. Addictive Behaviors, 33(10), 1276-1281.

Nakovics, H., Diehl, A., Geiselhart, H., \& Mann, K. (2009). Development and validation of an overall instrument to measure craving across multiple substances: The Mannheimer Craving Scale (MaCS). Psychiatrische Praxis, 36(2), 72-78. doi:10.1055/s-20081067546 
Oslin, D. W., Cary, M., Slaymaker, V., Colleran, C., \& Blow, F. C. (2009). Daily ratings measures of alcohol craving during an inpatient stay define subtypes of alcohol addiction that predict subsequent risk for resumption of drinking. Drug and Alcohol Dependence, 103(3), 131-136.

Peele, S., \& Brodsky, A. (2000). Exploring psychological benefits associated with moderate alcohol use: A necessary corrective to assessments of drinking outcomes? Drug and Alcohol Dependence, 60(3), 221-247.

Rehm, J., Mathers, C., Popova, S., Thavorncharoensap, M., Teerawattananon, Y., \& Patra, J. (2009). Global burden of disease and injury and economic cost attributable to alcohol use and alcohol-use disorders. The Lancet, 373(9682), 2223-2233.

Sayette, M. A., Shiffman, S., Tiffany, S. T., Niaura, R. S., Martin, C. S., \& Shadel, W. G. (2000). The measurement of drug craving. Addiction (Abingdon, England), 95(Suppl 2), S189.

Schmitt, N. (1996). Uses and abuses of coefficient alpha. Psychological assessment, 8(4), 350.

Skinner, M. D., \& Aubin, H.-J. (2010). Craving's place in addiction theory: Contributions of the major models. Neuroscience \& Biobehavioral Reviews, 34(4), 606-623.

Soyka, M., \& Küfner, H. (2008). Alkoholismus - Missbrauch und Abhängigkeit: Entstehung Folgen - Therapie (6th ed.). Stuttgart: Thieme.

Swiss Federal Council (2014). Federal Act on Research Involving Human Beings (Human

Research Act, HRA). https://www.admin.ch/opc/de/classifiedcompilation/20061313/201401010000/810.30.pdf. downloaded at 15/10/2017.

Tiffany, S. T., Carter, B. L., \& Singleton, E. G. (2000). Challenges in the manipulation, assessment and interpretation of craving relevant variables. Addiction, 95(8s2), 177-187. 
Tiffany, S. T., Fields, L., Singleton, E., Haertzen, C. A., \& Henningfield, J. E. (1993). The development of a heroin craving questionnaire. Purdue University: Unpublished manuscript.

Tiffany, S. T., Singleton, E., Haertzen, C. A., \& Henningfield, J. E. (1993). The development of a cocaine craving questionnaire. Drug \& Alcohol Dependence, 34(1), 19-28.

Wittchen, H.-U., \& Hoyer, J. (2011). Klinische Psychologie \& Psychotherapie: Springer-Verlag. World Health Organization. (2014a). Global status report on alcohol and health: World Health Organization.

World Health Organization. (2014b). Internationale Klassifikation psychischer Störungen : ICD-10 Kapitel $V(F)$ : Klinisch-diagnostische Leitlinien (9. Aufl. unter Berücksichtigung der Änderungen entsprechend ICD-10-GM 2014 ed.). Bern: H. Huber. 
Table 1

Characteristics of the sample

\begin{tabular}{|c|c|c|c|c|c|c|}
\hline & \multicolumn{6}{|c|}{ Main substance of abuse at admission } \\
\hline & \multirow{2}{*}{\multicolumn{2}{|c|}{$\begin{array}{l}\text { Alcohol } \\
n=112\end{array}$}} & \multirow{2}{*}{\multicolumn{2}{|c|}{$\begin{array}{c}\text { Licit substances } \\
n=22\end{array}$}} & \multirow{2}{*}{\multicolumn{2}{|c|}{$\begin{array}{l}\text { Illicit substances } \\
n \mathrm{n}=18\end{array}$}} \\
\hline & & & & & & \\
\hline & M/\% & $S D$ & $M / \%$ & $S D$ & $M / \%$ & $S D$ \\
\hline Age (years) & 46.2 & 10.1 & 40.7 & 13.7 & 34.4 & 10.4 \\
\hline \multicolumn{7}{|l|}{$\operatorname{Sex}(\%)$} \\
\hline Men & 59.8 & & 59.1 & & 56.2 & \\
\hline Women & 40.2 & & 40.9 & & 43.8 & \\
\hline Length of stay (days) & 27.6 & 25.7 & 21.2 & 13.3 & 25.73 & 17.5 \\
\hline \multicolumn{7}{|l|}{ Employment (\%) } \\
\hline Full-time job & 29.5 & & 22.7 & & 22.6 & \\
\hline Part-time job & 15.2 & & 9.1 & & 32.3 & \\
\hline Unemployed & 55.3 & & 68.2 & & 45.1 & \\
\hline \multicolumn{7}{|c|}{ Highest education obtained (\%) } \\
\hline Middle/high school & 27.2 & & 45.5 & & 40.0 & \\
\hline Vocational education & 56.3 & & 27.3 & & 30.0 & \\
\hline & & & & & \multicolumn{2}{|c|}{ (continued) } \\
\hline
\end{tabular}




\begin{tabular}{|c|c|c|c|c|c|c|}
\hline & \multicolumn{6}{|c|}{ Main substance of abuse at admission } \\
\hline & \multirow{2}{*}{\multicolumn{2}{|c|}{$\begin{array}{l}\text { Alcohol } \\
\mathrm{n}=112\end{array}$}} & \multirow{2}{*}{\multicolumn{2}{|c|}{$\begin{array}{l}\text { Licit substances } \\
\qquad n=22\end{array}$}} & \multirow{2}{*}{\multicolumn{2}{|c|}{$\begin{array}{l}\text { Illicit substances } \\
\qquad \mathrm{n}=18\end{array}$}} \\
\hline & & & & & & \\
\hline & $M / \%$ & $S D$ & $M / \%$ & $S D$ & $M / \%$ & $S D$ \\
\hline University-entrance diploma & 3.9 & & 18.1 & & 13.3 & \\
\hline College/University & 12.6 & & 9.1 & & 16.7 & \\
\hline \multicolumn{7}{|l|}{ Severity of the AUD (\%) } \\
\hline None & 1.0 & & 21.4 & & 30.4 & \\
\hline Mild & 2.0 & & 21.4 & & 8.7 & \\
\hline Moderate & 7.8 & & 7.2 & & 8.7 & \\
\hline Severe & 89.2 & & 50.0 & & 52.2 & \\
\hline
\end{tabular}

Note . Licit substances = tobacco, benzodiazepine, and other prescribed drugs for non-medical use;

Illicit drugs = cannabis, heroin, cocaine, LSD, ecstasy, amphetamine, and many others. AUD = Alcohol Use Disorder. 
Table 2

Mean (M), standard deviation (SD), item-total correlation $\left(r_{i t}\right)$, and factor loading of the MaCS

\begin{tabular}{ll}
\hline Item & \\
\hline $1 \quad$ Wenn Sie keine Suchtmittel nehmen, wie viel Ihrer Zeit wird dann von \\
& Vorstellungen, Gedanken, Impulsen oder Bildern beansprucht, die etwas damit zu \\
& tun haben? \\
& How much of your time when you are not taking addictive drugs is occupied by \\
& ideas, thoughts, impulses, or images related to consume?
\end{tabular}

Wie häufig treten diese Gedanken oder Vorstellungen auf?

$1.32 \quad 1$.

1.19

.66

0.74

0.80

0.12

3

How frequently do these thoughts occur?

3 Wie stark werden Ihre berufliche Tätigkeit oder Ihr soziales Verhalten von diesen

Vorstellungen, Gedanken, Impulsen oder Bildern beeinflusst? Gibt es etwas, was sie deswegen nicht tun oder nicht können?

How much do these ideas, thoughts, impulses, or images interfere with your social or work (or role) functioning? Is there anything that you do not or can not do because of them? (If you are not currently working, how much of your performance would be affected if you were working?)

4 Wenn Sie kein Suchtmittel nehmen, wie sehr bemühen Sie sich dann, diesen Gedanken zu widerstehen, Sie nicht zu beachten oder Ihre Aufmerksamkeit auf

$1.51 \quad 1.19$
19

.75

0.80

0.69 etwas Anderes zu lenken?

How much distress or disturbance do these ideas, thoughts, impulses, or images related to consuming addictive drugs cause you when you are not drinking? 


Item

5 Wenn Sie kein Suchtmittel nehmen, wie sehr bemühen Sie sich dann, diesen

$\mathrm{n} \quad M \quad S D \quad \mathrm{r}_{\mathrm{it}}$

1 factor Rotated 2 factors

Gedanken zu widerstehen, Sie nicht zu beachten oder Ihre Aufmerksamkeit auf etwas Anderes zu lenken?

How much of an effort do you make to resist these thoughts or try to disregard or turn your attention away from these thoughts as they enter your mind when you are not taking addictive drugs?

6 Wenn Sie kein Suchtmittel nehmen, wie erfolgreich können Sie dann diese

154

1.55

.64

0.71
Factor 1 Factor 2 Gedanken beenden oder sie zerstreuen?

How successful are you at stopping or diverting these thoughts when you are not taking addictive drugs?

7 Wie stark wird Ihre berufliche Tätigkeit durch die Einnahme von Suchtmitteln beeinflusst? Gibt es etwas, was Sie deswegen nicht tun oder nicht können? How much does your consumption of addictive drugs interfere with your work functioning? Is there anything that you do not or can not do because of your consumption?

8 Wie stark wird Ihr soziales Verhalten durch die Einnahme von Suchtmitteln beeinflusst? Gibt es etwas, was Sie deswegen nicht tun oder nicht können? How much does your consumption of addictive drugs interfere with your social functioning? Is there anything that you do not or can not do because of your consumption?

$\begin{array}{llllll}1.55 & 1.17 & .49 & 0.55 & 0.13 & 0.80\end{array}$




Item

9 Wenn Sie ein Suchtmittel nehmen möchten, aber daran gehindert wären, wie

1 factor

Rotated 2 factors ängstlich oder ungehalten würden Sie dann werden?

If you were prevented from taking addictive drugs when you desired, how anxious or upset would you become?

10 Wie sehr bemühen Sie sich der Einnahme von Suchtmittel zu widerstehen?

n $\quad M \quad S D \quad \mathrm{r}_{\mathrm{it}}$

Factor $1 \quad$ Factor 2

How much of an effort do you make to resist consumption of addictive drugs?

11 Wie stark ist Ihr Drang, Suchtmittel zu nehmen?

How strong is the drive to consume addictive drugs?

12 Wie viel Kontrolle haben Sie über Ihren Suchtmittelkonsum?

How much control do you have over the consumption of addictive drugs?

A13 Wie stark war während der letzten 7 Tage Ihr Verlangen nach Suchtmittel (der Wunsch danach, während der Zeit, in der sie nicht konsumierten) im Durchschnitt? In general, how was your craving for addictive drugs during the last 7 days (that is, the desire for addictive drugs while you were not taking them)? (analogue scale)

A14 Denken Sie bitte einmal an den Moment innerhalb der letzten 7 Tage zurück, als das Verlangen nach einem Suchtmittel am stärksten war. Wie stark war dieses Verlangen?

Please try to remember the moment during the last 7 days when your craving for addictive drugs was most intense. How strong was the craving that you felt then?(analogue scale)

156

1.40

.63

0.70

156

1.86

.66

0.72

0.57

0.45
0.53 0.47

$155 \quad 48.84 \quad 31.44$

$\begin{array}{lll}153 & 58.73 & 34.09\end{array}$ 


\begin{tabular}{|c|c|c|c|c|c|c|c|c|}
\hline \multirow[t]{2}{*}{ Item } & & \multirow[b]{2}{*}{$\mathrm{n}$} & \multirow[b]{2}{*}{$M$} & \multirow[b]{2}{*}{$S D$} & \multirow[b]{2}{*}{$\mathrm{r}_{\mathrm{it}}$} & \multirow[t]{2}{*}{1 factor } & \multicolumn{2}{|c|}{ Rotated 2 factors } \\
\hline & & & & & & & Factor 1 & Factor 2 \\
\hline \multirow[t]{6}{*}{ A15 } & Wie häufig hatten Sie während der letzten 7 Tage Verlangen nach einem & 151 & 51.43 & 33.22 & & & & \\
\hline & Suchtmittel (den Wunsch danach, während der Zeit, in der sie nicht & & & & & & & \\
\hline & konsumierten)? & & & & & & & \\
\hline & How often during the last 7 days did you experience a craving for addictive drugs & & & & & & & \\
\hline & (that is, the desire for addictive drugs while you were not taking them)?(analogue & & & & & & & \\
\hline & scale) & & & & & & & \\
\hline \multirow[t]{2}{*}{ A16 } & Wann haben Sie zuletzt ein Suchtmittel genommen? & 143 & 5.96 & 5.82 & & & & \\
\hline & When did you last take addictive drugs? (days) & & & & & & & \\
\hline
\end{tabular}

Note. Exploratory factor analysis (EFA) with varimax rotation and Kaiser normalization. 


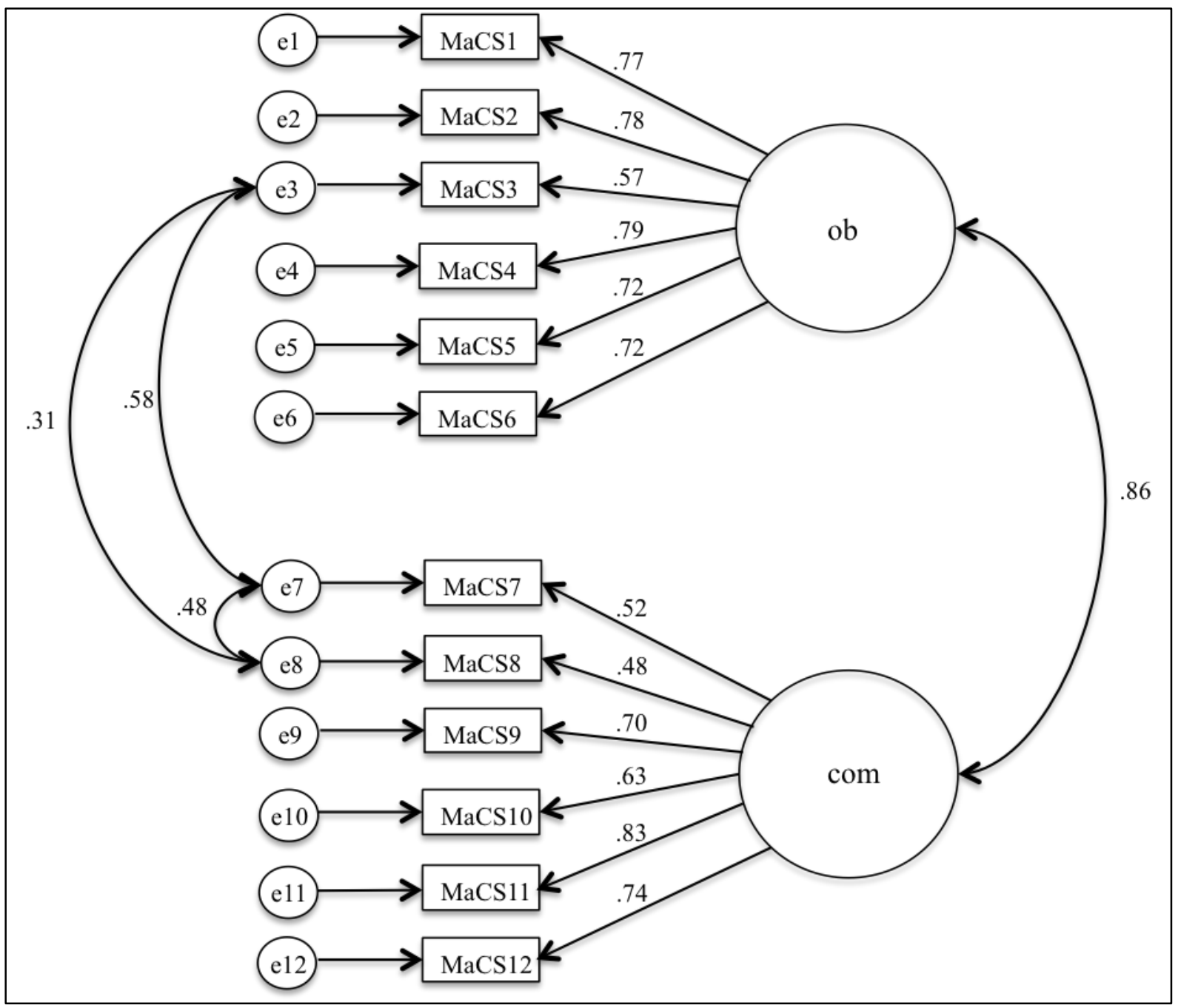

Figure 1. Two-factor model of the MaCS. The arrows from the latent variables to the manifest variables represent the standardized path coefficients. The arrows between the latent variables represent correlation coefficients. 


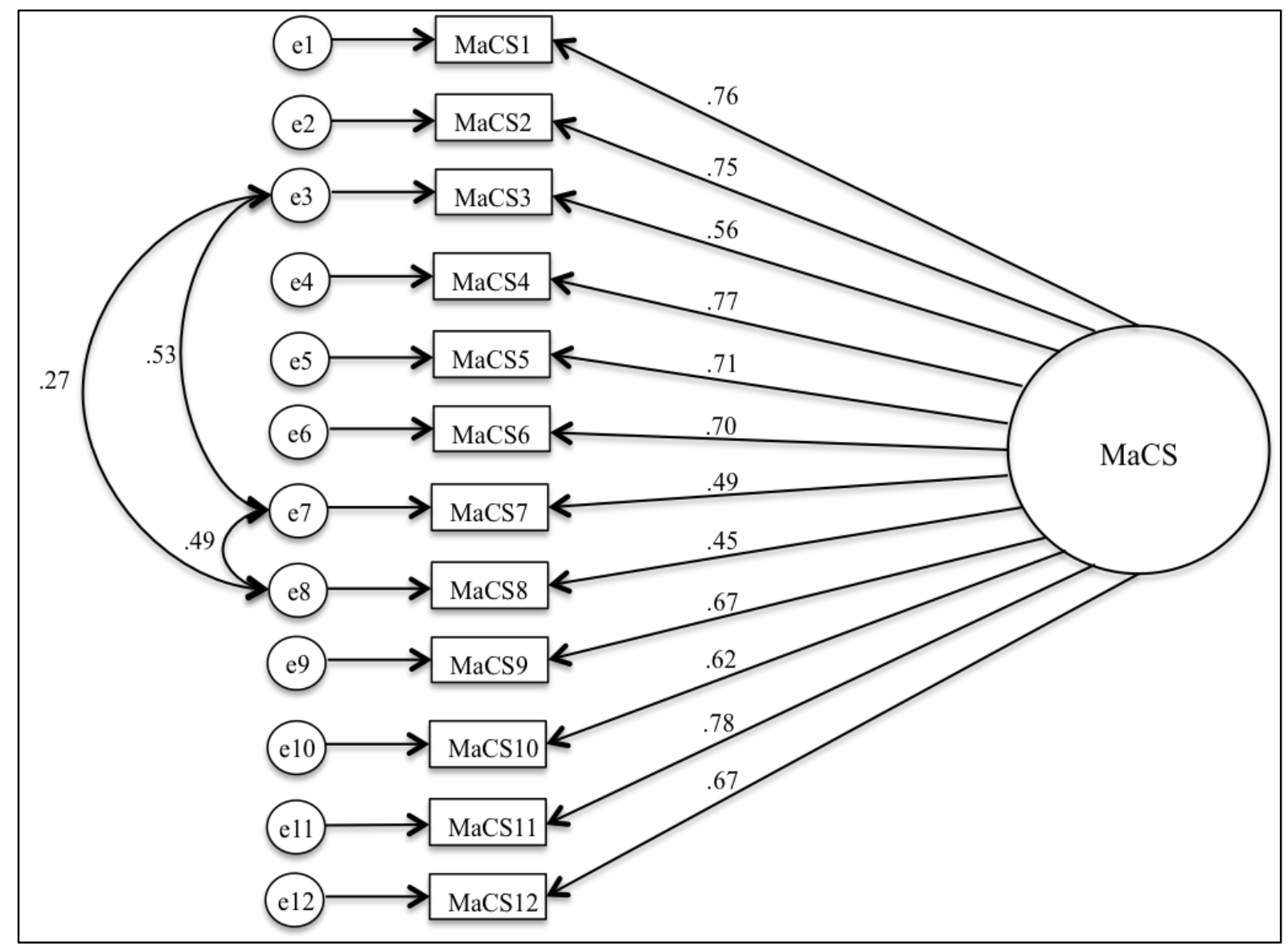

Figure 2. 1-factor model of the MaCS. The arrows between the latent variables to the manifest variables represent the standardized path coefficients. The arrows between the latent variables represent correlation coefficients. 